\title{
Grounding Microgrid Systems in Metropolitan and Commercial Areas
}

\author{
Giuseppe Parise (Life Fellow)
}

\author{
Luigi Parise (Senior Member)
}

Giuseppe Vagnati

\begin{abstract}
Adjacent-grounding systems, in metropolitan areas, are usually interfering, because moreover common external conductive parts interconnect naturally them. Their integration to constitute a grounding microgrid system GMS allows making each grounding system more extended than its ground electrode. It assists resolutely to present limited touch voltages permissible to persist longer than $10 \mathrm{~s}$ and so to create the conditions of an intrinsically safe grounding system ISGS. An intentional common integration of adjacent-grounding systems is admissible, because each one of the grounding systems must satisfy equal protection requirements prescribed by utilities. This paper deals with three sample cases of measurements on grounding systems in areas with high GSs density and of a large size. The tests allows identifying a grounding microgrid system assessing for each component ground electrode a dispersing capacity of the fault current more extended than its size up to the dimension of the efficiency saturation with the minimum impedance value. The identification by measures of grounding microgrid systems contribute to recognize and improve natural integrations and promote the progress of the common safety, regardless of formal validation.
\end{abstract}

Index terms - Electrical safety, grounding system, global grounding system, ground potential, zone of influence.

\section{INTRODUCTION. ADEQUACY OF A GROUNDING SYSTEM TO IEC STANDARD}

A ground fault current origins touch/step voltages $\mathrm{U}_{\mathrm{t}, \mathrm{s}}$ within the grounding system (GS) and around its zone of influence (ZOI) $[1,2]$ that have not to present hazards of electric shock. Complying with the standard IEC 61936-1- EN50522 [3, 4], the conventional touch voltage limit $\mathrm{U}_{\mathrm{L}}$ for $\mathrm{HV}$ a.c installations is assumed equal to $\mathrm{U}_{\mathrm{L}}=80 \mathrm{~V}$.

Time durations $t_{a}$ of fault permanence lower than $10 \mathrm{~s}[3,4]$ guaranteed by the tripping of the protective devices $t_{d} \leq t_{a}$ allow permissible limit values $U_{L t}$ of the touch voltages higher than $\mathrm{U}_{\mathrm{L}}=80 \mathrm{~V}$. The Table I show the limit touch voltage values for HV installations [3, 4].

In conclusion, it is defined a stringent correlation between the time duration of fault $t_{a}$ and the permissible limit values $U_{L t}$ of the touch voltages. An empirical expression to evaluate the $\mathrm{U}_{\mathrm{Lt}}$ in relation to the fault time durations $t$ is the following

$$
\mathrm{U}_{\mathrm{Lt}}=a \mathrm{t}^{6}-\mathrm{bt} \mathrm{t}^{5}+\mathrm{ct} \mathrm{t}^{4}-\mathrm{dt} \mathrm{t}^{3}+\mathrm{et} \mathrm{t}^{2}-\mathrm{ft}+\mathrm{g}
$$

assuming for the constants $\mathrm{a}, \mathrm{b}, \mathrm{c}, \mathrm{d}, \mathrm{e}, \mathrm{f}, \mathrm{g}$ the values shown in the Table II for times lower than $1 \mathrm{~s}$ and higher than $1 \mathrm{~s}$.

The adequacy of a GS has to be verified in reference to the fault duration $t_{d}$ and so to the related permissible voltage $U_{L t}$ and in reference to the ground fault current $\mathrm{I}_{\mathrm{G}}=\mathrm{r} \mathrm{I}_{\mathrm{F}}$, being $\mathrm{r}$ a reduction factor of the fault current $I_{F}$.
For a tripping time $t_{d}$ of the protective device, the GS is conventionally safe, if its $R_{G}\left(Z_{G}\right)$ resistance is sized to limit the ground potential rise GPR for the fault current $\mathrm{I}_{\mathrm{G}}$ satisfying

$$
\mathrm{t}=\mathrm{t}_{\mathrm{d}} \quad \mathrm{U}_{\mathrm{G}}=\mathrm{Z}_{\mathrm{G}} \text { r I } \mathrm{I}_{\mathrm{F}} \cong \mathrm{R}_{\mathrm{G}} \mathrm{I}_{\mathrm{G}} \leq \mathrm{F} \mathrm{U}_{\mathrm{Lt}}(\mathrm{t})
$$

The factor $\mathrm{F}=\mathrm{U}_{\mathrm{G}} / \mathrm{U}_{\mathrm{Lt}}$ takes into account that the admissible values for the $\mathrm{U}_{\mathrm{G}}$ can be higher than the $\mathrm{U}_{\mathrm{t}, \mathrm{s}}$ inside the GS.

The IEC/EN approach [3,4] generally prospects $\mathrm{F}=2$. If the condition (2) is not satisfied, it is mandatory to test and provide that the touch voltages $U_{t}$ inside and around the grounding system are lower than the admissible limits $U_{\mathrm{Lt}}$.

It is well known that the fall-of-potential FoP method measures the ground-impedance applying a voltage $U$ between the GS under test and a remote current probe that origins the flow of a current $\mathrm{I}_{\mathrm{F}}$ through it. An auxiliary potential electrode is placed at various locations between current probe and the GS border, plotting the ratio of $\mathrm{U} / \mathrm{I}_{\mathrm{F}}=\mathrm{R}$ as a function of probe position. The FoP provides acceptable results only if a flat portion in the potential profile has been tested very clearly and at this aim the current probe must be efficiently outside the influence of the tested GS. For a large GS or a GS in areas with high density of interfering GSs, the spacing required is normally unpractical or almost impossible. In any case, also if the measurement of the ground resistance in areas of low accessibility is unlikely; nevertheless, the assumption of the resistance $\mathrm{R}_{\mathrm{G}}$, as a reference parameter, plays a key role in analyzing and defining in a general way the GSs behavior.

TABLE I MAXIMUM PERMISSIBLE VALUES OF VOLTAGES ULt $\left(t_{d}\right)$ ACCORDING TO THE TRIPPING TIME $t_{d}$

\begin{tabular}{|c|c|c|c|}
\hline$t_{d}(s)$ & $U_{L t}(\mathrm{~V})$ & $t_{d}(s)$ & $U_{L t}(V)$ \\
\hline 0.04 & 800.00 & 0.50 & 213.00 \\
\hline 0.08 & 700.00 & 0.80 & 120.00 \\
\hline 0.14 & 600.00 & 1.00 & 103.00 \\
\hline 0.20 & 500.00 & 1.60 & 94.00 \\
\hline 0.29 & 400.00 & 5.00 & 82.00 \\
\hline 0.39 & 300.00 & 10.00 & 80.00 \\
\hline 0.45 & 248.00 & $>10.00$ & 80.00 \\
\hline
\end{tabular}

TABLE II CONSTANTS OF THE EMPIRICAL EXPRESSION (1) FOR

\begin{tabular}{|c|c|c|c|c|c|}
\hline$t[s]$ & a & b & & & \\
\hline $\begin{array}{c}\leq 1 \\
>1 \text { to } 10\end{array}$ & $\begin{array}{c}7533 \\
0\end{array}$ & $\begin{array}{c}27451 \\
0\end{array}$ & & & \\
\hline$t[s]$ & c & d & e & $f$ & g \\
\hline$\leq 1$ & 38466 & 26581 & 10624 & 3409.8 & 922.3 \\
\hline$>1$ to 10 & 0.023 & 0.606 & 5.7945 & 24.432 & 120.64 \\
\hline
\end{tabular}
TIMES LOWER THAN 1S AND HIGHER THAN $1 \mathrm{~s}$. 
The present trend in Europe is to operate the MV distribution with a resonant grounding system that determines fault currents in the order of 50-70 amperes and the adoption of ground fault protection-tripping times greater than $10 \mathrm{~s}$.

Let us consider that it is possible to identify the GS for an assigned $\mathrm{I}_{\mathrm{F}}$ as intrinsically safe system $\operatorname{ISGS}\left(\mathrm{I}_{\mathrm{F}}\right)[5,6]$, if the touch voltage assumes values not higher than the safe values permissible to persist indeterminately or even so for a time duration higher $10 \mathrm{~s}$.

In the resonant grounding systems that normally adopt a protection tripping time $t_{d} \geq 10$ s for the MV feeders, the GS must be an ISGS and its GPR must satisfy the condition (2) putting $U_{\mathrm{G}} \leq \mathrm{F} \mathrm{U}_{\mathrm{L}}$. As already noted, the IEC approach $[2,3]$ states in $\mathrm{HV}$ a. c. , the conventional touch voltage limit $\mathrm{U}_{\mathrm{L}}$ equal to $80 \mathrm{~V}$ and $\mathrm{t}_{\mathrm{L}}>10 \mathrm{~s}$; while it states in $\mathrm{LV}$ a. c., $\mathrm{U}_{\mathrm{L}}$ equal to $50 \mathrm{~V}$ (normal conditions) and $\mathrm{t}_{\mathrm{L}}=5 \mathrm{~s}$.

Therefore, a general conservative definition of an ISGS has to consider the coexistence of MV-GSs and LV-GSs and to require that the $R_{G}$ is equal or lower than the reference value $\mathrm{R}_{\text {GMAX }}$

$$
\mathrm{R}_{\mathrm{G}} \leq \mathrm{F} \cdot \mathrm{U}_{\mathrm{L}} / \mathrm{r} \mathrm{I}_{\mathrm{F}}=\mathrm{F} \cdot 50 / \mathrm{r} \mathrm{I}_{\mathrm{F}}=100 / \mathrm{r}_{\mathrm{F}}=\mathrm{R}_{\mathrm{GMAX}}
$$

Moreover, the IEC/EN standards [3,4], introduce the global grounding system (GGS) as an equivalent grounding system that ensures no dangerous touch voltages, but regardless the ground fault current $\mathrm{I}_{\mathrm{F}}$ at which instead the ISGS( $\left.\mathrm{I}_{\mathrm{F}}\right)$ definition correlates the safety condition. A relevant limitation however to define a group of GSs as GGS is that requires formal validation by the utility, due to the contribution of the distribution cable shields, only essential for isolated GSs.

In synthesis, the GS of a MV installation has to be designed complying with the IEC criteria [3] and the parameters prescribed by the utilities for each delivery point (POD) of the MV installations:

- the prospected fault current $\mathrm{I}_{\mathrm{F}}$,

- the tripping times of the protective device of the utility MV feeder in reference to which size the GS and of the ground fault relay (GFR) against ground fault internal in the GS.

In this manner, the assigned tripping time of the utility's MV feeder automatically fixes the limit value $\mathrm{U}_{\mathrm{Lt}}(\mathrm{t})[3,4]$ in relation to which the GS system of the MV installation must be sized. For resonant grounding system, the typical tripping time value is $t_{d}>10 \mathrm{~s}$ that delimit the permissible voltage to $\mathrm{U}_{\mathrm{Lt}}=\mathrm{U}_{\mathrm{L}}=80 \mathrm{~V}$. The utility generally requires the adoption of a directional protection of the same POD by a ground fault relay (GFR) against ground fault internal to the GS. In particular the utility imposes to calibrate the tripping time of the GFR to a maximum value of the order of $t_{\mathrm{GFR}}=0.45 \mathrm{~s}$ that is correlated to a permissible voltage $\mathrm{U}_{\mathrm{Lt}}=248 \mathrm{~V}$. The resonant grounding system guarantees a fault current of no more than 50-70 A differently from the previous management of the ungrounded neutral system with a fault current of hundreds amps. This option modifies the safety conditions of the grounding systems with the advantage of reducing the value of the fault current to 50-70 A, but with the change that the utility operates the MV system with protection times greater than $10 \mathrm{~s}$.
It has to be noted that in case of fault in the utility network the prospected duration of the GPR can be higher than $t>10 \mathrm{~s}$, because in case of a fault internal to the GS the prescribed ground fault relay trips in $0.45 \mathrm{~s}$.

\section{GLOBAL AND INTRINSICALLY SAFE GROUNDING SYSTEMS. GROUNDING MICROGRID SYSTEMS.}

The metropolitan and commercial areas present a high density of MV/LV transformer power stations.

In these areas, the grounding systems are rarely isolated, but they are close to each other in their zones of influence and are interfering, interconnected or integrated.

In fact, it becomes very rare to have an area around a GS with sufficient accessibility, but in its ZOI others GSs or, generically, extraneous conductive parts ExCPs are present [5]. Generally, not buried conductors interconnect each GS to other GSs and buried conductors (intentional or unintentional) integrate them.

The interconnection and integration of GSs allow creating the conditions of an intrinsically safe grounding system (ISGS) [5, $6,7]$. Therefore, it is peaceful to suggest a free organization of adjacent GSs in an integrated GS toward the constitution of a unique grounding system as a grounding microgrid system (GMS).

A relevant aspect is that the measured value of the resistance of a GS, interconnected or integrated with other GSs, presents a sensitive reduction in comparison to the resistance value calculated in the condition of isolated GS. A significant issue is the difference in the resistance reduction between GSs isolated and interconnected by the distribution cable shields and GSs adjacent and integrated. In fact, the linear interconnection introduces series resistances $R_{S}$ less negligible that increase with the distance from the ground fault point and saturate the contribution to disperse the fault current (Figure 1).

Figure 2 shows graphically the sample behavior of isolated $\mathrm{N}$ GSs, in a loop configuration, with independent zones of

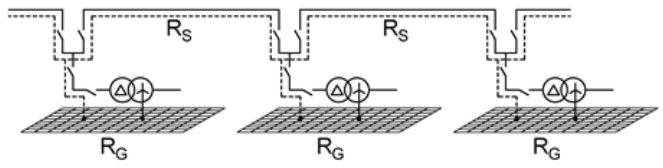

Figure 1 . The scheme of a linear interconnection of N GSs.

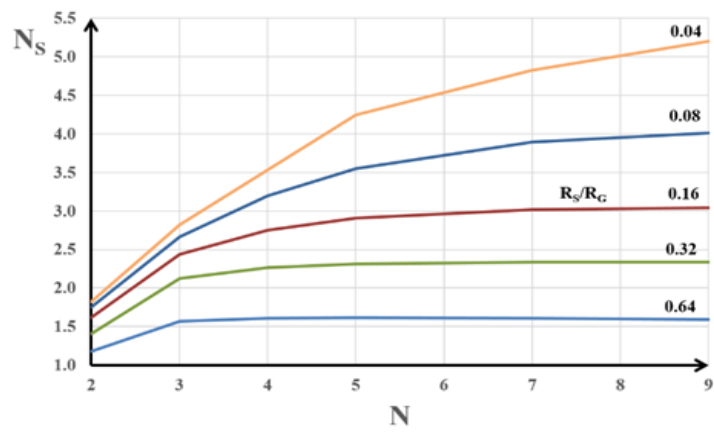

Figure. 2. A series of $\mathrm{R}_{\mathrm{S}} / \mathrm{R}_{\mathrm{G}}$ curves for the $\mathrm{N}-\mathrm{N}_{\mathrm{s}}$ in the case study of GSs assuming an equal value for $\mathrm{R}_{\mathrm{S}}$ and $\mathrm{R}_{\mathrm{G}}[8]$ 
influence, an equal $R_{G}$ value of the ground resistances and characterized by a same resistance ratio of the interconnections $\mathrm{R}_{\mathrm{S}} / \mathrm{R}_{\mathrm{G}}$. The series of $\mathrm{R}_{\mathrm{S}} / \mathrm{R}_{\mathrm{G}}$ curves on the $\mathrm{N}-\mathrm{N}_{\mathrm{s}}$ show as the series $R_{S}$ resistances saturate the number $N$ of GSs to a maximum number $\mathrm{N}_{\mathrm{s}}$ efficacious to disperse also increasing the number $\mathrm{N}>\mathrm{N}_{\mathrm{s}}$ of the interconnected GSs [6].

The integration of adjacent GSs in a meshed common GS makes slight the saturation, favoring a larger partition of the ground fault current via conductors with a lower localized density of dispersion to ground. An increased integration in a larger extension tends to convert the single GSs into a GMS and reduces the common ground resistance rather than the amount of leakage current on the single GS (so, it has to be assumed $\mathrm{r}=1$ ). A start point of saturation of efficiency of GMS in reducing its impedance $R_{\text {Gsps }}$ regardless its extension has to be expected when the same impedance seen from the fault point assumes values lower than $\mathrm{R}_{\mathrm{Gsps}}=0.5 \Omega$. At this low value, the resistance/impedance may have an appreciable reactive component [8] and the self-impedance of electrode conductors becomes not negligible.

A threshold minimum value of the impedance $R_{\mathrm{Gmin}}$ of a large GS or a GMS, due to the efficiency saturation to disperse the fault current, could be assumed of the order of $\mathrm{R}_{\mathrm{Gmin}}=0.1 \Omega$.

This behavior promotes the integration as a safety solution for metropolitan and commercial areas in the aim to reach the condition of intrinsically safe grounding system - ISGS $\mathrm{R}_{\mathrm{G}}<\mathrm{R}_{\mathrm{GMAX}}$.

Let us note that the integration over its extension even beyond the size of the saturation is able to guarantee everywhere the minimum threshold value of the impedance $\mathrm{R}_{\mathrm{Gmin}}$ seen from the fault point.

In metropolitan or commercial areas, extended ISGSs can become grounding microgrid system, a public "grounding service" organized and managed similarly to the water, gas, energy, telephone or internet services.

\section{GROUNDING MICROGRID SYSTEMS IN METROPOLITAN AND COMMERCIAL AREAS: INTRINSICALLY SAFE GROUNDING SYSTEMS [9, 10]}

In areas with reduced accessibility, the contiguity of GSs enables their meshed integration with intentional buried conductors to form a GMS, already naturally integrated. This integrated system reduces the global resistance $\mathrm{R}_{\mathrm{G}}$ and therefore each GS component can reach easier the safety conditions required for its adequacy.

Let us note that each GS, inside a common area, has to comply with the same safety conditions imposed at the POD of its power system. Therefore, each one of these GSs can be assumed satisfying identical protection requirements and so equally adequate to be protected against internal MV ground faults in relation to the trip time of the ground fault relay (GFR).

In other words, the integration between contiguous grounding systems is bound to the fact that each one is equipped with a directional ground relay with the same settings imposed by the distributor. In this case, the advantage that users achieve is that the internal ground faults guarantee $U_{G} \leq F U_{L}$ for the tripping time of the GFR (=0.45 s), enhancing the general safety.
Therefore, all the energized power systems that can integrate their GSs are in condition of safety parity and the integration of adjacent GSs in a grounding microgrid system GMS is surely an efficient solution to satisfy the safety condition $U_{G} \leq F_{L}$ (=cautiously F 50V). Considering that the promotion of the resonant grounding system in metropolitan areas facilitates the achievement of an ISGS condition $\left(\mathrm{I}_{\mathrm{F}} \leq 70 \mathrm{~A}\right)$, an integrated grounding system has to be promoted, organized and managed. In reality, there are no reasons impeding the utilities cannot promote and participate in the constitution of the GMS that tests confirm their natural existence. The connection of the shields of the utility power cables to the GS, required by the IEC/EN standards [3, 4], improves the integration of each GS, but transfers from the network to the GS external faults protected in a time higher than $10 \mathrm{~s}$, because the ground fault relay of the same GS cannot protect.

Then, a GS or its integrated GMS must have a constitution and an efficient dispersing area sufficient to satisfy, for an assigned soil resistivity, the intrinsic safety condition that can be characterized by a minimum diameter $\mathrm{D}_{\min }$ of an equivalent circle. On the other hand, in zones with a high density of GSs, a large GS or the integrated GMS can reach such dimensions and an equivalent diameter $\mathrm{D}$ not only higher than the $\mathrm{D}_{\min }$, but also exceeding the characteristic maximum diameter $\mathrm{D}_{\mathrm{MAX}}$, that saturates the efficiency in dispersing the fault current.

A rule of thumb [4] to evaluate the diameter D of a circle with the area equivalent to a meshed ground electrode of resistance $\mathrm{R}_{\mathrm{G}}$, it can be adopted the formula

$$
\mathrm{R}_{\mathrm{G}}=\rho / 2 \mathrm{D}
$$

being the soil resistivity $\rho$.

Therefore, the necessary minimum prospected diameter $\mathrm{D}_{\min }$ of the equivalent area that the single GS or the integrated GMS must occupy for the fulfilment of the intrinsic safety condition $\left(\mathrm{U}_{\mathrm{GMAX}}=\mathrm{F} \mathrm{U}_{\mathrm{L}}=100 \mathrm{~V}\right)$, can be achieved in reference to the maximum admissible value of resistance $\mathrm{R}_{\mathrm{GMAX}}$ defined by the formula (3)

$$
\mathrm{R}_{\mathrm{GMAX}}=\rho / 2 \mathrm{D}_{\min }=100 / \mathrm{r} \mathrm{I}_{\mathrm{F}}
$$

$\mathrm{D}_{\min }$ is obtained as:

$$
D_{\min }=(\rho / 100 \cdot r) I_{F} / 2
$$

Let us note that, assuming for a GMS reasonably $r=1$, in reference to a soil resistivity $\rho=100 \Omega \mathrm{m}$, the value in meters of the diameter $D_{\min }$ of the GS is equal to the half value of the $I_{F}$. The diameter $D_{\min }$ will vary proportionally to the ratio $\rho / 100$ of the soil resistivity and to the ratio $1 / \mathrm{r}$ for $\mathrm{r}<1$.

Then, two other threshold values characterize a large GS and a GMS, the diameter $D_{\text {spes }}$ and the diameter $D_{\text {MAX }}$ related respectively to the impedance $\mathrm{R}_{\mathrm{Gspes}}=0.5 \Omega$, start point of efficiency saturation and to the minimum impedance $R_{G m i n}$ assumed in an indicative way of the order of $\mathrm{R}_{\mathrm{Gmin}}=0.1 \Omega$ :

$$
\begin{aligned}
& \mathrm{D}_{\text {spes }}=\rho / 2 * 0.5=|\rho| \\
& \mathrm{D}_{\text {MAX }} \approx \rho / 2 * 0.1=5|\rho|
\end{aligned}
$$


Let us note that the value in meters of the diameter $D_{\text {spes }}$ of the GS is equal to the value of the soil resistivity $\rho$. Whereas, the value in meters of the diameter $\mathrm{D}_{\mathrm{MAX}}$ of the maximum area efficient to disperse the fault current of the GMS around the fault point is roughly of the order of five times the value $|\rho|$ of the soil resistivity.

Tests can identify a grounding microgrid system that does not need the validation as a global grounding system avoiding the technical and formal difficulties that the utilities usually present to do it. The identification in fact is confirmed when the measured value of the resistance of a GS diverges significantly from the calculated value due to the integration among the GSs of the GMS [8].

The availability of a detailed map of the GS that shows its configuration, any extraneous conductive parts and other adjacent GSs contributes to identify their integrated condition of a GMS. Its presumable impedance can reach the saturated minimum value $\mathrm{R}_{\mathrm{Gmin}}$, if the global extension is comparable with an area of diameter $\mathrm{D}_{\mathrm{MAX}}$ in meter of the order of 4-5 times the $|\rho|$ value.

No standard prohibits improving the integration of adjacent grounding systems and therefore naturally interacting by means of metallic buried structures and common ground wires. In metropolitan and commercial areas with reduced accessibility, in a general agreement, the same utility will do well to promote technically and formally the GMS as ISGS equivalent to a global grounding system prefigured by the same IEC standard, overcoming the problem of validating the same GGS.

\section{SAMPLE CASES OF GMS IDENTIFICATION}

This paper presents three sample cases of experimental measurements on grounding systems that verify the achievement of the intrinsic safety condition related to the $\mathrm{I}_{\mathrm{F}}$ $\left(D_{\min }\left(\mathrm{I}_{\mathrm{F}} / 2\right)\right.$, more easily when the MV distribution operates with a resonant grounding system, but also the accomplishment of the minimum efficient impedance of the order of $0.1 \Omega$ in GMSs or large GSs. The second and third cases present a low resistivity $\rho$ and so a related low value of $D_{\operatorname{MAX}}(\approx 4$ or $5|\rho|)$ easier to reach.

\section{A. First sample case}

The GS of the first sample case is related to a building in an urban area adjacent to many other GSs. It is composed of 8 copper-plated steel rods with diameter $d=0.02 \mathrm{~m}$ and length $\mathrm{h}$ $=1.5 \mathrm{~m}$, connected to each other by a ring electrode constituted of a bare copper conductor $\left(50 \mathrm{~mm}^{2} \mathrm{~d}=0,008 \mathrm{~m}\right)$ buried in the ground at a depth of $0.5 \mathrm{~m}$ (Figure 3 ).

The GS is located, in the basement, in the interspace surrounding the building. Some structures (stairs) and the incoming pipes - gas - water, the shields of the network connecting cable are joined to the GS.

The rods are located in the 4 corners of the basement of the building and 2 rods on each one of the longer sides. The grounding system therefore has the same rectangular shape of the building with the sizes $\mathrm{a}, \mathrm{b}$ long $\mathrm{a}=60 \mathrm{~m}$ and wide $\mathrm{b}=25 \mathrm{~m}$.

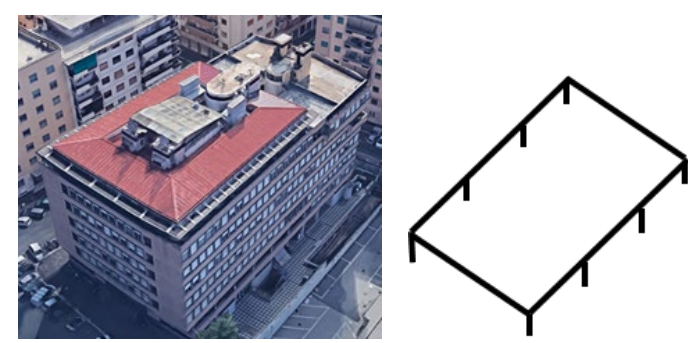

Figure 3. Sample case of GS of a building rising in a metropolitan area: the ground electrode is constituted by a ring and eight rods

The soil resistivity was measured as $\rho=66.6 \Omega / \mathrm{m}$ and the measurement conditions were clear weather with slightly damp soil. The prospected value of the ground resistance can be estimated by calculating the parallel of the two contributions of the ring ground electrode and of the eight rods.

The contribution of the ring electrode can be calculated [4] with the following simplified formulas

$$
\mathrm{R}_{\mathrm{G}, \text { ring }}=\frac{\rho}{\pi^{2} \mathrm{D}} \ln \frac{2 \pi \mathrm{D}}{\mathrm{d}}=1.33 \Omega
$$

where

$$
\mathrm{D}=\frac{2(\mathrm{a}+\mathrm{b})}{\pi}=54.11 \mathrm{~m}
$$

The contribution of the eight- rods can be calculated [4] with the simplified formulas

$$
\mathrm{R}_{\mathrm{rod}}=\left(\frac{\rho}{2 \pi \mathrm{h}} \ln \frac{4 \mathrm{~h}}{\mathrm{~d}}\right) / 8=40.3 \Omega
$$

and

$$
\mathrm{R}_{\text {rods }}=\mathrm{R}_{\mathrm{rod}} / 8=5.04 \Omega
$$

Therefore, the prospected global resistance $R_{G p}$ remains estimated by the parallel of the two contributions $R_{\text {ring }}$ and $R_{\text {rods }}$ and therefore equal to

$$
\mathrm{R}_{\mathrm{Gp}}=1 /\left[\left(1 / \mathrm{R}_{\text {ring }}\right)+\left(1 / \mathrm{R}_{\text {rods }}\right)\right]=1.05 \Omega
$$

Therefore, adopting the (4), the prospected diameter $D_{p}$ of the circle equivalent to the area of the grounding system is

$$
D_{p}=\rho / 2 R_{G}=32 m
$$

Let us note that the $\mathrm{D}_{\mathrm{p}}$ satisfies the intrinsic safety condition (6) also for $\mathrm{I}_{\mathrm{G}}=\mathrm{I}_{\mathrm{F}}=70 \quad \mathrm{~A}$ and $\mathrm{r}=1 \quad\left(\mathrm{D}_{\mathrm{p}}=32 \mathrm{~m}>\mathrm{D}_{\min }=\right.$ $(66.6 / 100) * 70 / 2)=23.1 \mathrm{~m})$. To measure the ground resistance with the FoP method, the current probe was positioned at $70 \mathrm{~m}$ from the border of the GS and therefore at more than one and a half times the $D_{p}$ of the equivalent circle.

The measurements have been made by adopting the potential probe $(0.2 \mathrm{~m})$ at a step of $5 \mathrm{~m}$, less than $1 / 10$ of the distance between the current probe and the ground electrode under test. As in other measurement cases in areas with a high density of buildings, moving the probe away from the GS under test, the measurement of the resistance shows a slight decay of the value 


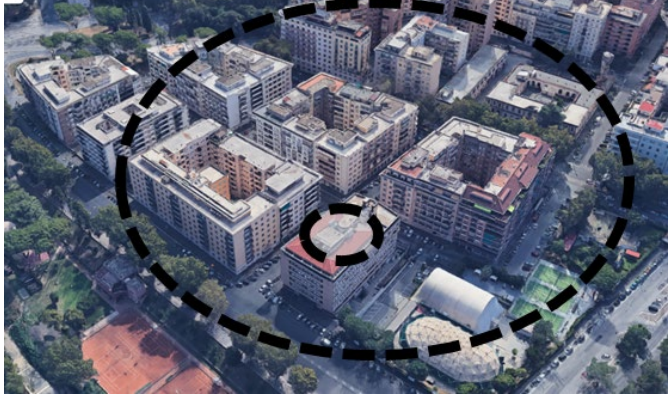

Figure 4. The measurement on a GS in high-density area of buildings can identify its membership to a GMS: the two circles $D_{p}=32 \mathrm{~m}$ and $D_{\text {mes }}=256 \mathrm{~m}$ show the equivalent areas of the sample case of ground electrode related to the resistance calculated and measured respectively

without a clear inflection in the potential profile. The ground resistance value measured with the voltage probe at $40,45,50$ $\mathrm{m}$ was $0.11 \Omega$, at $55 \mathrm{~m}$ it was $0.12 \Omega$ and at $60 \mathrm{~m}$ and $65 \mathrm{~m}$ it was $\mathrm{R}_{\mathrm{Gmes}}=0.13 \Omega$.

Therefore, the considerable difference of about 8 times, between the prospected value $\mathrm{R}_{\mathrm{Gp}}=1.05 \Omega$ of the ground resistance and that measured $\mathrm{R}_{\mathrm{Gmes}}=0.13 \Omega$, displays that there are other connections with neighboring ground systems.

Considering therefore that the complex of ground systems of the interfering buildings can be configured as an overall meshed system GS, the measured value $\mathrm{R}_{\text {Gmes }}=0.13 \Omega$, suggests that this grounding system could be equivalent to a circle of diameter

$$
\mathrm{D}_{\text {mes }}=\rho / 2 \mathrm{R}_{\mathrm{Gmes}}=256 \mathrm{~m}
$$

which actually includes the presence of ground installations of adjacent buildings (Figure 4), near to the $\mathrm{D}_{\mathrm{MAX}}$.

\section{B. Second sample case}

The GS of the second sample case is related to many adjacent PV blocks inside a park (Figure 5). The GS of each block is composed of a ring electrode constituted of a bare copper conductor buried in the ground at a depth of $0.5 \mathrm{~m}$ with a quasirectangular shape with the sizes $\mathrm{a}, \mathrm{b}$ long about $\mathrm{a}=200 \mathrm{~m}$ and wide about $b=100 \mathrm{~m}$. The PV modules inside the block are grounded and interconnected to make meshed the block GS.

The soil resistivity was measured as $\rho=20 \Omega / \mathrm{m}$ and the measurement conditions were clear weather.

The prospected value of the ground resistance $R_{\mathrm{Gp}}$ of each block GS can be estimated by calculating the GS diameter analogously to the (8)

$$
\mathrm{D}=\frac{2(\mathrm{a}+\mathrm{b})}{\pi}=190.98 \mathrm{~m}
$$

and adopting the (4)

$$
\mathrm{R}_{\mathrm{Gp}}=\rho / 2 \mathrm{D}=20 / 2 * 190.98=0.05 \Omega
$$

The GSs of the blocks are interconnected and so two kinds of masurement are made on each GS of the block under test with and without the connection to the other GSs. The ground

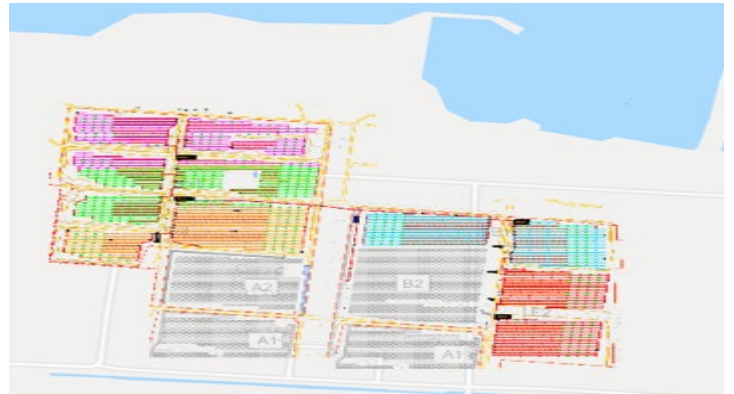

Figure 5. The measurement on the GSs of PV blocks in a park has confirmed the efficiency saturation for each one of them

resistance value measured was on average $R_{\text {Gmes }}=0.11 \Omega$ that confirms the diameter $\mathrm{D}_{\mathrm{MAX}}$ of the maximum area efficient to disperse the fault current of the GMS around the fault point

$$
\mathrm{D}_{\mathrm{MAX}}=20 / 2 * 0.11=90.9 \mathrm{~m}=4.5|\rho| \text { (18) }
$$

lower than half value of the diameter of each GS. Let us note that anyhow the integration of all the park blocks is able to guarantee everywhere the minimum value of the impedance $\mathrm{R}_{\mathrm{Gmin}}$ seen from the fault point.

\section{Third sample case}

The third sample case is that of a large GS of an electrical station serving a thermoelectric power plant with a combined CHP. The grounding system has the sizes long $\mathrm{a}=240 \mathrm{~m}$ and wide $b=80 \mathrm{~m}$ constituted by a ground grid electrode with meshes 5 by $5 \mathrm{~m}$ in the central area and $10 \mathrm{~m}$ by $10 \mathrm{~m}$ in the area around (Figure 6).

The soil resistivity was measured as $\rho=25.1 \Omega / \mathrm{m}$ and the measurement conditions were clear weather.

The relations (16) and (17) applied at this case calculate respectively $\mathrm{D}$ equal to $203.71 \mathrm{~m}$ and $\mathrm{R}_{\mathrm{Gp}}$ equal to $0.06 \mathrm{ohm}$. The current probe was positioned at $330 \mathrm{~m}$ from the border of the GS and therefore at more than one and a half times the D of the equivalent circle.

The ground resistance value measured with the voltage probe at $180 \mathrm{~m}$ was $\mathrm{R}_{\mathrm{Gmes}}=0.12 \Omega$ that confirms the diameter $\mathrm{D}_{\mathrm{MAX}}$ of the maximum efficient area of the GS is lower than the actual diameter of the GS

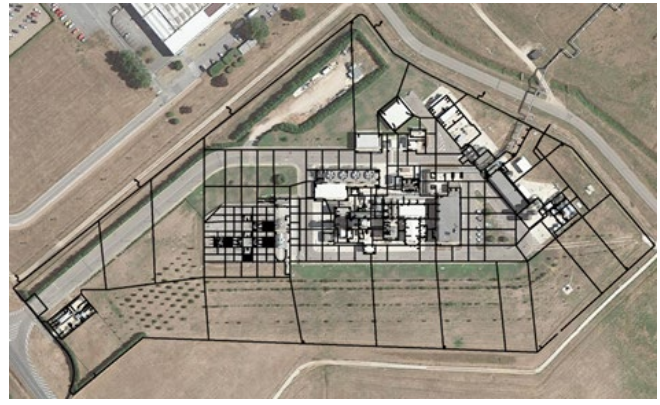

Figure 6. The measurement on a large GS in a soil of low resistivity confirms its efficiency limited to a part of the ground electrode around the fault point 


$$
\mathrm{D}_{\mathrm{MAX}}=20 / 2 * 0.12=104.58 \mathrm{~m}=4.2|\rho|
$$

about half value of the diameter of the actual GS that anyway guarantees for a fault in each internal component to be protected the minimum value of the impedance $R_{\mathrm{Gmin}}$.

\section{CONCLUSIONS}

The IEC approach provides for a global grounding system, involving users and utilities, as an optimal solution to guarantee the safety of systems in metropolitan and commercial areas, but states that only the utility can validate its existence. The present trend in Europe is to operate the MV distribution with a resonant grounding system that determines fault currents in the order of 50-70 amperes and the adoption of ground fault protection-tripping times greater than $10 \mathrm{~s}$.

Therefore, the GS has to be equivalent to an intrinsic safety grounding system ISGS, because for the tripping time $\geq 10 \mathrm{~s}$ it has to satisfy the conventional touch voltage limit $\mathrm{HV}-\mathrm{U}_{\mathrm{L}}=80$ $\mathrm{V}$ or cautiously the $\mathrm{LV}-\mathrm{U}_{\mathrm{L}}=50 \mathrm{~V}$ due to the coexistence of MVGSs and LV-GSs. In metropolitan and commercial areas, a grounding microgrid systems GMS improving the natural integration among adjacent grounding systems of users, contributes positively to guaranteeing safety. A GMS does not require approval of the utility, because it can be identified by measurements on each GS component. These measurements will confirm for each one of GS under test the membership to the GMS when it is verified a functional efficacy well beyond over its own constitution. The utility can still adhere to the integration and promote a general review of the safety requirements in the condition of global grounding system.

International standards must provide for a new vision of the grounding system in metropolitan and commercial areas of electrical use, recognizing the effective and positive interaction between grounding systems.

\section{REFERENCES}

[1] IEC 61140:2016 Protection against electric shock - Common aspects for installation and equipment

[2] IEC 60364-4-41 "Low-voltage electrical installations - Part 441: Protection for safety - Protection against electric shock", 2005, Ed.5

[3] IEC 61936-1:2010-11 Power installations exceeding $1 \mathrm{kV}$ a.c. Part 1: Common rules

[4] EN 50522: 2010-11, "Earthing of Power Installations Exceeding $1 \mathrm{kV}$ a.c.

[5] Meterglob project, Italian CCSE (Cassa Conguaglio Settore Elettrico) partners: Enel Distribuzione, Universities of Palermo and of Rome Sapienza, Polytechnics of Torino and Bari, Istituto Italiano del Marchio di Qualità IMQ.

[6] G. Parise, Parise, L., Martirano, L. Intrinsically Safe Grounding Systems and Global Grounding Systems (2017) IEEE Transactions on Industry Applications, Year: 2018, Volume: 54, Issue: 1 Pages: 25 - 31.

[7] G. Parise, L. Parise, L. Martirano, F. Tummolillo, G. Vagnati, A. Barresi. "Tests and Monitoring of Grounding Systems in HV/MV Substations". Industry Applications, IEEE Transactions on Year: 2017, Volume: 53, Issue: 2 Pg: 929 - 935

[8] IEEE Std 81TM-2012 (Revision of IEEE Std 81-1983) IEEE Guide for Measuring Ground Resistivity, Ground Impedance, and Ground Surface Potentials of a Grounding System

[9] G. Parise, L. Parise, G. Vagnati "Integrated Grounding Systems: An Underogable Opportunity For Users In Urban And Industrial Areas" IEEE IAS Annual Meeting, Portland OR USA September 23-27 2018 DOI: 10.1109/IAS.2018.8544645

[10] G. Parise, L. Parise, G. Vagnati "Grounding Microgrid Systems in Metropolitan and Commercial Areas" IEEE IAS Annual Meeting, Baltimore, MD, USA 29 Sept.-3 Oct. 2019 pages 1-6 DOI: 10.1109/IAS.2019.8911840

\section{BIOGRAPHIES}

Giuseppe Parise (M'82-SM'03-Fellow 10-Life Fellow 15)) received his M.S. degree in Electrical Engineering from the Sapienza University, Rome Italy in 1972. Since 1973 up to 2017, he has been with the Faculty of Engineering, Sapienza University of Rome, where he was a Full Professor of Electrical Power Systems and actually, he is adjunct professor. He has authored about 350 papers and of two patents and three Prize Paper Awards by IEEE/IAS PSD. He has been Designer of power electrical systems in buildings complexes. He has been since 1983 and is currently member in law a Member of Superior Council of Ministry of Public Works (Italy). He is active in the IEEE Industry Applications Society (past Member at Large of Executive Board), chair of the two subcommittee I\&CPS Forensics and Ports, Distinguished Lecturer 2019-2020. He is chair of the R8 Area Chapter and of the Italy Section Chapter IA34. He is IAS Associate Member of Governors Board of Society of Social Impact of Technology SSIT. He is vice President of Association Safety Technology Research for Industry (ASTRI), President of Electrical Italian Association AEIT Rome's Section. Since 1975, he has been a Registered Professional Engineer in Italy. (parise@ieee.org)

Luigi Parise (StM'06-M'10-SM'16) received the B.S. degree, the M.S. degree and Ph.D. degree in Electrical Engineering from the Sapienza University of Rome, Rome Italy, in 2007, 2009 and 2014 respectively. He was a recipient of the 2010 Italian Electrotechnical Committee (CEI) Award for the Best Thesis. He was Research Fellow at University of Calabria (UNICAL) and at Sapienza University of Rome. He is currently electrical engineer designer at the Bambino Gesù Paediatric Hospital of Rome and Tutor in electrical power systems in hospitals in the University Biomedical Campus of Rome. He is a member of the Electrical Italian Association (AEIT), past chair of the R8/Europe Area of IEEE Industry Applications Society SBCs and the Secretary of Italy Section IAS Chapter. Since 2008, he has been a Registered Professional Engineer in Italy. (1.parise@ieee.org)

Giuseppe Vagnati received the graduate degree in computer science from the University of Pisa, Pisa, Italy, in 1990, and the graduate degree in computer engineering and industrial automation from the University E-Campus, Novedrate, Italy, in 2014. He is currently with Istituto Italiano del Marchio di Qualità, Milano, Italy, as a Senior Inspector on 'electrical plants low, medium, and high voltage, and does inspection on lightning protection systems and inspection on electrical plant in areas with explosive atmospheres (ATEX). (giuseppe.vagnati@imq.it) 